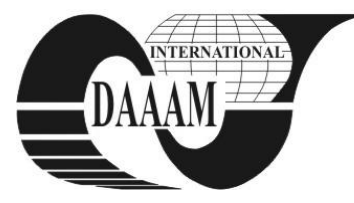

Annals of DAAAM for 2011 \& Proceedings of the 22nd International DAAAM Symposium, Volume 22, No. 1, ISSN 1726-9679 ISBN 978-3-901509-83-4, Editor B. Katalinic, Published by DAAAM International, Vienna, Austria, EU, 2011 Make Harmony between Technology and Nature, and Your Mind will Fly Free as a Bird

\title{
PARAMETRIC OPTIMIZATION OF ECH PROCESS FOR GEAR FINISHING BY RSM AND SAA
}

\author{
MISRA, J[oy] P[rakash]; JAIN, P[ramod] K[umar] \& DWIVEDI, D[heerendra] K[umar]
}

\begin{abstract}
This paper presents the parametric optimization of Electrochemical Honing (ECH) of gears using Response Surface Methodology (RSM) and Simulated Annealing Algorithm (SAA) to predict the surface quality of gear teeth profile. A three factors three levels Box Behnken Design (BBD) of Response Surface Methodology (RSM) has been designed to investigate and analyse the effects of input variables: voltage, rotating speed and electrolyte concentration on percentage improvement in average and maximum surface roughness $\left(P I R_{a}\right.$ $\left({ }^{\prime} I R_{t m}\right)$ values. Regression models were developed and were used as objective function for optimizing the process parameters using SAA. The results established the feasibility of using the process to improve the surface quality of gear teeth profile.

Key words: electrochemical honing (ECH), response surface methodology (RSM), box-behnken design (BBD), simulated annealing algorithm (SAA)
\end{abstract}

\section{INTRODUCTION}

The Helical gears are used to transmit motion and/or power between two parallel or crossed axes shafts or between shaft and rack by gradual engagement of teeth. This type of gears has higher load carrying capacity and used for high speed application. But, gears running at high speed are subjected to additional dynamic forces due to discontinuities in tooth profile. The discontinuities namely scratches, cut marks, notches, pits present at the gear teeth profile act as stress concentrator and enhances the chances of fatigue failure. The errors of gear tooth profile can be significantly reduced by gear finishing processes. Conventional gear finishing processes such as gear grinding, gear shaving, gear honing, gear lapping are costly, have low productivity, and gear material hardness limitation. This necessitates exploration of alternative gear finishing processes such as Electrochemical honing $(\mathrm{ECH})$ which is a hybrid micro-finishing process combining electrochemical machining (ECM) and honing, having potential to overcome most of the limitations of both the process and at the same time offers most of the capabilities of individuals.

\subsection{ECH of Gears}

$\mathrm{ECH}$ is a hybrid finishing process of ECM and mechanical honing; combining the faster material removal capability of ECM and the correcting capability for shape-related errors of honing into a single process. Fig. 1 describes the working principle of ECH of gears described by Chen et al. (1981), in which an anodic workpiece gear meshes with a specially shaped cathodic gear and a honing gear simultaneously and also reciprocates axially as indicated by the arrow. An interelectrode gap (IEG) is provided between the workpiece and cathode gear to prevent short-circuiting by sandwiching a conducting gear between two non-conducting gears and undercutting the profile of the conducting gear as compared with that of the non-conducting gears. A low D.C. voltage is applied across the electrolyte flooded IEG for controlled electrochemical (EC) dissolution of the anodic gear. But, due to electrolytic passivation a thin insulated metal oxide microfilm is formed on the teeth profile of the workpiece gear and protects the metal from being further removed. Honing gear scrubs this insulated layer and accelerates the ECM process.

There are very few references available on ECH of gears. Though the process was initiated by Capello and Bertoglio in 1979 , the modelling of the process was probably started by Yi et al. in 2002. They explained the electrochemical tooth-profile modification based on real time control and developed a mathematical model of the process using an artificial neural network. Misra et al. (2010) have investigated on ECH of helical gears but to the best knowledge of authors the optimization of the process parameters using evolutionary optimization technique is not reported till date. In the present study, parametric optimization of the process has been carried out using RSM and SAA.

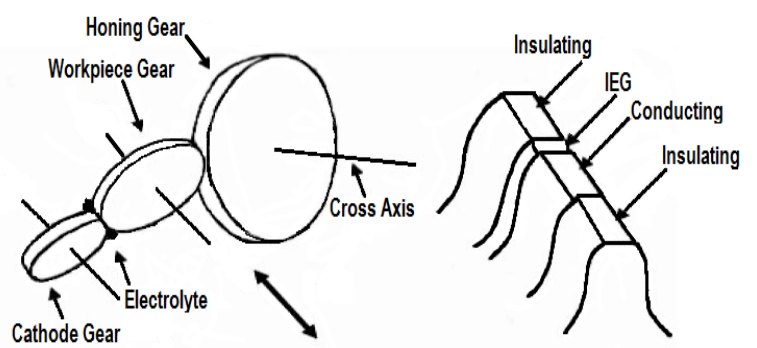

Fig. 1. Working principle of ECH of gears (Chen et al., 1981)

\section{EXPERIMENTATION}

The experimentation has been carried out in an indigenously developed experimental setup for $\mathrm{ECH}$ of helical gears. The detail of the same has been available in reference (Misra et al., 2010).

In the present study, voltage $(\mathrm{V})$, rotating speed of workpiece gear (S) and electrolyte concentration (C) are used as input process parameters while percentage improvement in average and maximum surface roughness values $\left(\mathrm{PIR}_{\mathrm{a}} / \mathrm{PIR}_{\mathrm{tm}}\right)$ are used as response parameters. The surface roughness values before and after ECH are measured with a Wyko NT 1100 optical profilometer interfaced with Vision ${ }^{\circledR} 32$ software. The experimentation was planned according to the Box-Behnken Design of Response Surface Methodology (RSM) approach. The experimental study contained three factors each at three levels and therefore number of experimental run required was fifteen including three replications of centre point.

\section{RESULTS AND DISCUSSIONS}

The effects of process parameters on $\mathrm{PIR}_{\mathrm{a}}$ and $\mathrm{PIR}_{\mathrm{tm}}$ are shown in Fig. 2(a) and (b), respectively. The regression models developed for $\mathrm{PIR}_{\mathrm{a}}$ and $\mathrm{PIR}_{\mathrm{tm}}$ in terms of actual values are described by equations (1) and (2) respectively. 


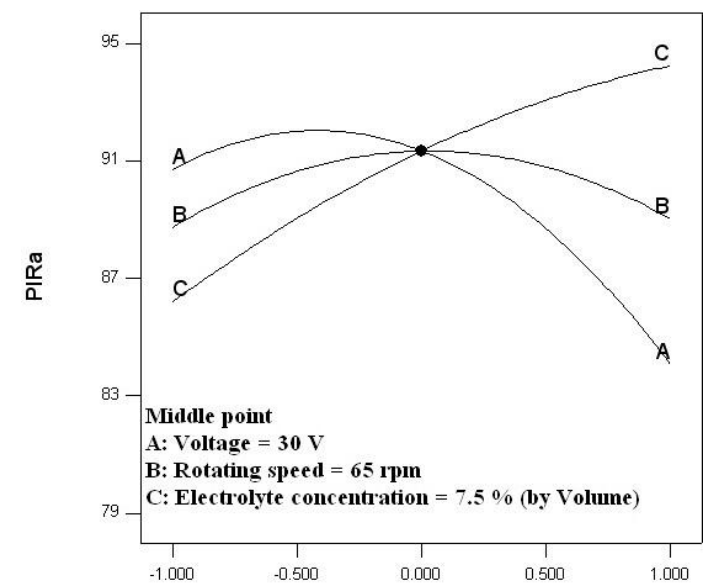

(a)

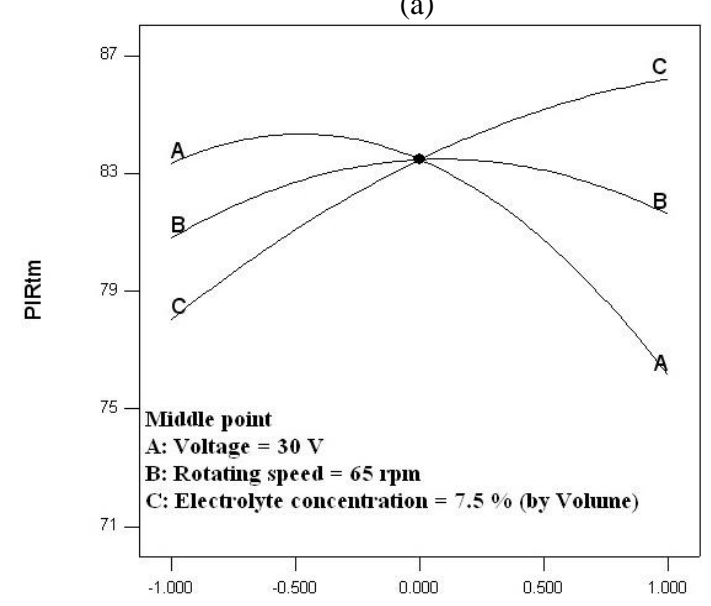

(b)

Fig. 2. Effects of process parameters on (a) $\mathrm{PIR}_{\mathrm{a}}$ and (b) $\mathrm{PIR}_{\mathrm{tm}}$ (X-axis: Deviation from reference point)

$P I R_{\mathrm{a}}=-173.75771+13.90969 \times V+1.43058 \times S+4.2770 \times C-$ $0.23315 \times V^{2}-0.010933 \times S^{2}-0.17800 \times C^{2}$

$P I R_{\mathrm{tm}}=-167.99383+13.08875 \times V+1.33719 \times S+4.84850 \times C$ $-0.23315 \times V^{2}-0.010080 \times S^{2}-0.21447 \times C^{2}$

The improvement in surface roughness values (i.e. $\mathrm{PIR}_{\mathrm{a}} / \mathrm{PIR}_{\mathrm{tm}}$ ) initially increase with voltage upto a certain level and then start decresing as volumetric material removal rate is proportional to the voltage while voltage is inversely proportional to the IEG. It is evident from Fig. 1 and 2, that there exists an optimum value of rotating speed of the workpiece gear to achieve the optimum coordination between the electrolytic action and mechanical abrasion. The $\mathrm{PIR}_{\mathrm{a}} / \mathrm{PIR}_{\mathrm{tm}}$ values increase with increasing electrolyte concentration as more number of ions is available in electrolytic solution.

\subsection{Simulated Annealing Algorithm}

In the present study, SA is used as an optimization technique for solving a bound-constrained optimization problem. The technique imitates the cooling process of metal during annealing to achieve the minimization of function values (Chandrasekaran et al., 2010). The regression models developed by RSM have been used as objective function and the upper and lower bounds of parameters are identified by conducting experiments. The problem can be formulated as given below. The main aim is to maximize the $\operatorname{PIR}_{\mathrm{a}}$ and $\mathrm{PIR}_{\mathrm{tm}}$ value.

So, the objective functions:

Minimize $\mathrm{Z}=\mathrm{W}_{1} *\left(-\mathrm{PIR}_{\mathrm{a}}\right)+\mathrm{W}_{2} *\left(-\mathrm{PIR}_{\mathrm{tm}}\right)$;

$\mathrm{W}_{1}, \mathrm{~W}_{2}$ are arbitrarily choosen parameters to represent the importance of each response parameter and taken as 0.5 .

Subjected to, $26 \leq \mathrm{V} \leq 34 ; 50 \leq \mathrm{S} \leq 80 ; \mathrm{C} \leq 10$.
The optimization is carried out in MATLAB (Version: 7.6.0.324) environment. Fig. 3 depicts the current function value at each iteration.

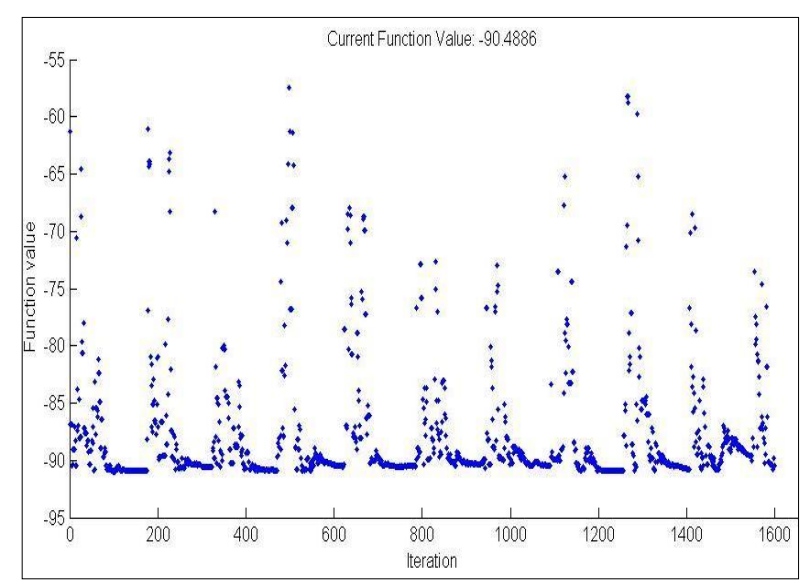

Fig. 3. Function value at each iteration

\section{CONCLUSION AND FUTURE SCOPE}

In the present work, parametric optimization using Response Surface Methodology and Simulated Annealing Algorithm has been carried out. Based on the results, $28.4 \mathrm{~V}$ as voltage, $65 \mathrm{rpm}$ as rotating speed and $10 \%$ as electrolyte concentration are found optimum and at optimum setting of the parameters, the process shows an improvement of $91 \%$ in surface quality of gear teeth profile. Thus, the process is very much useful for improving the fatigue life and service life of gears. But, in present study, parametric optimization has been carried out only for voltage, rotating speed and electrolyte concentration. An eleaborate experimental investigation is required to optimize other ECH parameters. Moreover, the developed experimental setup is not capable to accommodate the gear of different sizes and therefore, a vigorous study is required to develop an experimental setup with modular tooling system to accommodate gear of different sizes and to carry out $\mathrm{ECM}$, honing and $\mathrm{ECH}$ process in a single setup to transform it into a matured manufacturing technology and for its successful industrial applications and commercialization.

\section{REFERENCES}

Capello, G. \& Bertoglio, S. (1979). A New Approach by Electrochemical Finishing of Hardened Cylindrical Gear Tooth Face. CIRP Annals, Vol. 28, No. 1, 103-107, 00078506

Chandrasekaran, M.; Muralidhar, M.; Murali Krishna, C. \& Dixit, U. S. (2010). Application of Soft Computing Techniques in Machining Performance Prediction and Optimization: A Literature Review. International Journal of Advanced Manufacturing Technology, Vol. 46, 445-464, 02683768

Chen, C. P.; Liu, J.; Wei, G. C.; Wan, C. B. \& Wan, J. (1981). Electrochemical Honing of Gears: A New Method of Gear Finishing. CIRP Annals, Vol. 30, No.1, 103-106, 00078506

Misra, J. P.; Jain, N. K. \& Jain, P. K. (2010). Investigations on precision finishing of helical gears by electrochemical honing $(\mathrm{ECH})$ process, Proc. IMechE: Journal of Engineering Manufacture, Vol. 224, No. 12, 1817-1830, 20412975

Yi, J.; Zhang, J.; Yang, T.; Xia, D. \& Hu, D. (2002). Solving the control problem for electrochemical gear tooth-profile modification using an artificial neural network. International Journal of Advanced Manufacturing Technology, Vol. 19, No. 1, 8-13, 14333015 